\title{
COMPARATIVE ANALYSIS OF WASTE REDUCTION METHODS FOR SUSTAINABLE MANUFACTURING SYSTEMS USING CONCURRENT TRIANGULATION MODEL.
}

\author{
Q. A. Kingsley-Omoyibo \\ Department of MeChanical EngR'G, IgBinedion Univ., OKADA, OKAdA TOWn, Edo StaTe, NIGERIA \\ E-mail address: queeneth.omoyibo@iuokada.edu.ng
}

\begin{abstract}
The aim of this study is to carry out a comparative analysis of waste reduction methods for sustainable manufacturing systems using Cronbach alpha and concurrent triangulation model. The objective of this research is to establish an ideal sustainable manufacturing waste disposal method. Reliability test results showed that the Cronbach alpha values used to measure the internal consistency of responses recorded for recycling, reuse, reduce, remanufacture and landfilling were $0.8160,0.8100,0.7760,0.7550$ and 0.7340 respectively with recycling recording the highest internal consistency. The concurrent triangulation model recorded results showed that recycling recorded a total of 184 respondents at the highest percentage of $51.11 \%$, reuse recorded a total of 58 respondents with $16.13 \%$, remanufacture recorded 43 respondents at $11.94 \%$, reduce recorded a total of 38 respondents at $10.55 \%$, and Landfilling had 37 respondents with $10.27 \%$. Hence Recycling was selected as the most appropriate method.
\end{abstract}

Keywords: Concurrent Triangulation model, cronbach alpha, Recycling, Reuse, Remanufacturing, Sustainable manufacturing system.

\section{INTRODUCTION}

The landfill was used as a last option for waste that was not recyclable or reused. Hence, waste reduction, reuse, and disposal of waste that cannot be recycled into landfills were waste reduction strategies that enhanced sustainable manufacturing [1]. To sustain the environment, operations of the manufacturing industries should be geared towards reducing waste, using recycling, reuse, reduce, remanufacture and use of landfills where materials cannot be recycled or reused[1].In this research the concurrent triangulation model was used to consolidate results obtained from assessed knowledge of respondents and collected data was integrated with the use of quantitative methods and qualitative method merged to confirm results obtained in the process of doing this research. A good test was aimed at, using the cronbach alpha to achieve a reasonable internal consistency of raters in the study. Source reduction, using fewer materials, and reduced energy, will save cherished space and build a renewable environment [2]. Source reduction can be accomplished using three fundamental areas of sustainability which are: Social development, economic development and environmental protection. Social development deals with people being aware of the environment, protecting the environment and educating the people on social values and norms that guide the protection of the environment for sustainability. Economic development will foster incentives, reduce stress financially on the populace, not compromising quality of life by eradicating barriers to legislations that affect the environment. Using target goals, economic development improves the economic well-being of a people using policy interventions targeted at social economic growth [3].

Manufacturing Industries and Factory activities, affect the economy as their daily actions of illegal waste disposal, disposal of chemicals, disposal of heavy metals, release of noxious gases, contamination of waste water and disposal of radioactive materials, pose

*Author, tel: $+234-814-139-1481$ 
a serious hazard to the environment. In practice, sustainable materials will use viable materials that will be friendly with the natural earth and not deplete the earth. Sustainable manufacturing employs less energy; less wastage of products manufactured, uses nonhazardous materials for manufacturing and supports recyclable products [4].

Environmental protection deals with recycling, reuse, remanufacture, reduce and Landfilling for a sustainable earth. It involves using latest technologies to drive a continuous future. Waste should be characterized, after generating it, collect the waste, transport the waste from source point to point of usage and then disposed. Before disposing, waste generated should be treated in order to prevent pollution in the environment. For sustainable manufacturing systems, the disposals methods are re-use, reduce, remanufacture, recycle and land filling. The waste is then treated for sustainable production in order to maintain environmental quality [5].

\section{POLLUTION CONTROL}

Controlling production in manufacturing processes will target at eliminating noxious gases, encourage reduction of waste and enhance innovations in manufacturing. Moving manufacturing to close loop system from the conventional linear system, will achieve waste as an input rather than having waste dumps in dumpsites or disposing waste indiscriminately [6].

\section{SUSTAINABLE MANUFACTURING}

Sustainable manufacturing deals with using economically sound processes to create products from processes of manufacturing to minimize environmental impact that are negative while conserving natural resources and energy for safety of the produced products [7].The main objective of sustainable manufacturing is to reduce waste. Manufacturing industries will be sustainable when waste generated is reduced, re-used, remanufactured and recycled. Water, raw materials, non-renewable minerals and energy should be sustained so as to produce clean air, clean natural resources and a non-toxic environment that will reduce toxic environmental impacts [8].

Sustainability produces environmental awareness that helps us to safeguard our natural environment, remain diverse, and maintain balance in the ecosystem and safe the naturality of the world by protecting the earth from damages and ills of pollution in the environment [9]. Waste generated is reduced using reuse and source reduction and materials for recycle collected, are processed with the generated reduced waste.

Figure1. Shows the closed loop system where sustainable manufacturing system is implemented for alternative energy production and minimization of waste, conserve raw materials and re-use raw materials. Waste is used as the raw material. Process optimization is achieved using the closed loop system in a view to changing manufacturing processes to minimize waste, conserve raw materials and reduce raw materials. Raw materials are substituted in order to substitute greener materials for Hazardous materials.

\section{WASTE DISPOSAL METHODS}

Waste is collected using communal collection, block collection, house to house collection and curbside collection. In this research, waste disposal methods employed are: collection of the waste using house to house collection, treating the waste, reducing the waste by reducing the volume of the waste collected and recycling the recyclable products [10]. Waste reduction techniques in sustainable manufacturing are:

1. Recycle: Materials collected as waste to be trashed are processed and turned into new products and then sent back into the environment. Waste is reduced to the barest minimum and pollution control in sustained.

2. Re-manufacturing: Remanufacturing is an industrial and comprehensive process where an item that is non-functional is returned into a manufacturing process, processed into a new product and sent into the main stream. Examples are aircraft parts and rethreading of tyres. Remanufacturing saves energy tackles pollution control issues and helps to reduce waste.

3. Re-use: Reuse of materials deals with product recovery and use of new products derived for different purposes apart from using these re-usable output for its original purpose [12]. 


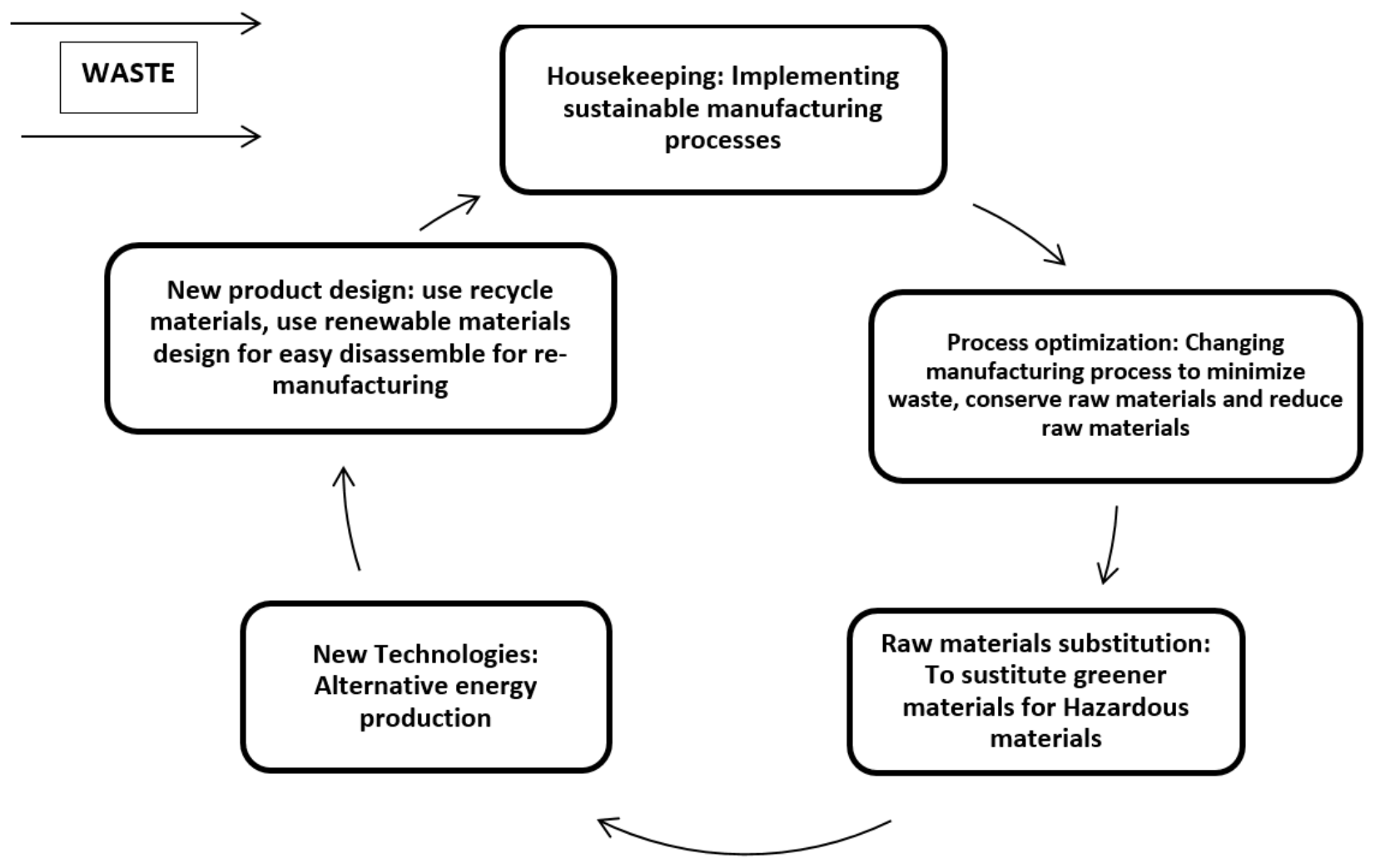

Figure 1: Closed loop system (source: UNEP, 2009)

\section{MATERIALS AND METHODS}

This research focused on waste reduction, controlling pollution and encouraging sustainable manufacturing systems using the concurrent triangulation model and cronbach alpha. The cronbach alpha was used to measure internal consistency of respondents that agreed with the true values of the construct tied to the questions in the study. For a good test, the respondents had to be adequate in order to achieve a reasonable internal consistency as calculated with cronbach alpha in this study hence, the choice of the study population of 360 respondents. Using the rule of thumb $0 \geq 0.9$ is excellent, $0 \geq 0.8$ is good, $0 \geq$ 0.7 is acceptable, $\quad 0 \geq 0.6$ is quetionable, $\quad 0 \geq$ 0.5 is poor, and $0 \geq 0.4$ is unacceptable, the values obtained were analyzed. The concurrent triangulation model as described by Thilo kroll and Melinda Neri, 2005 was used to collect Quantitative data to analyze the data generated using survey questionnaires with close ended questions which were administered to manufacturing industry workers, waste managers, employees of Ministry of
Environment and some university lecturers specialized in the area of waste management and environmental science. Data collected and analyzed used descriptive statistics in the phase 1 of the model. Phase 2 of the model which is the qualitative data, used a thematic analysis where Cronbach alpha was used to test the internal consistency of the five sustainable manufacturing waste disposal methods used in this study. In this study, a total of 410 questionnaires were distributed, 350 questionnaires via email and 60 questionnaires distributed randomly using the face-toface approach. The questionnaires captured verbal and non-verbal responses using the SPSS version 24 to analyze the data collected. The results from phase 1 and phase 2 of the concurrent triangulation model were merged and integrated to corroborate findings within the study in order to overcome the weakness using only phase 1 which is the quantitative phase with the strength of using phase 2 which is the qualitative data to confirm the final results which were recorded. Figure 2 shows the diagram of the concurrent triangulation model which is divided into two phases. 


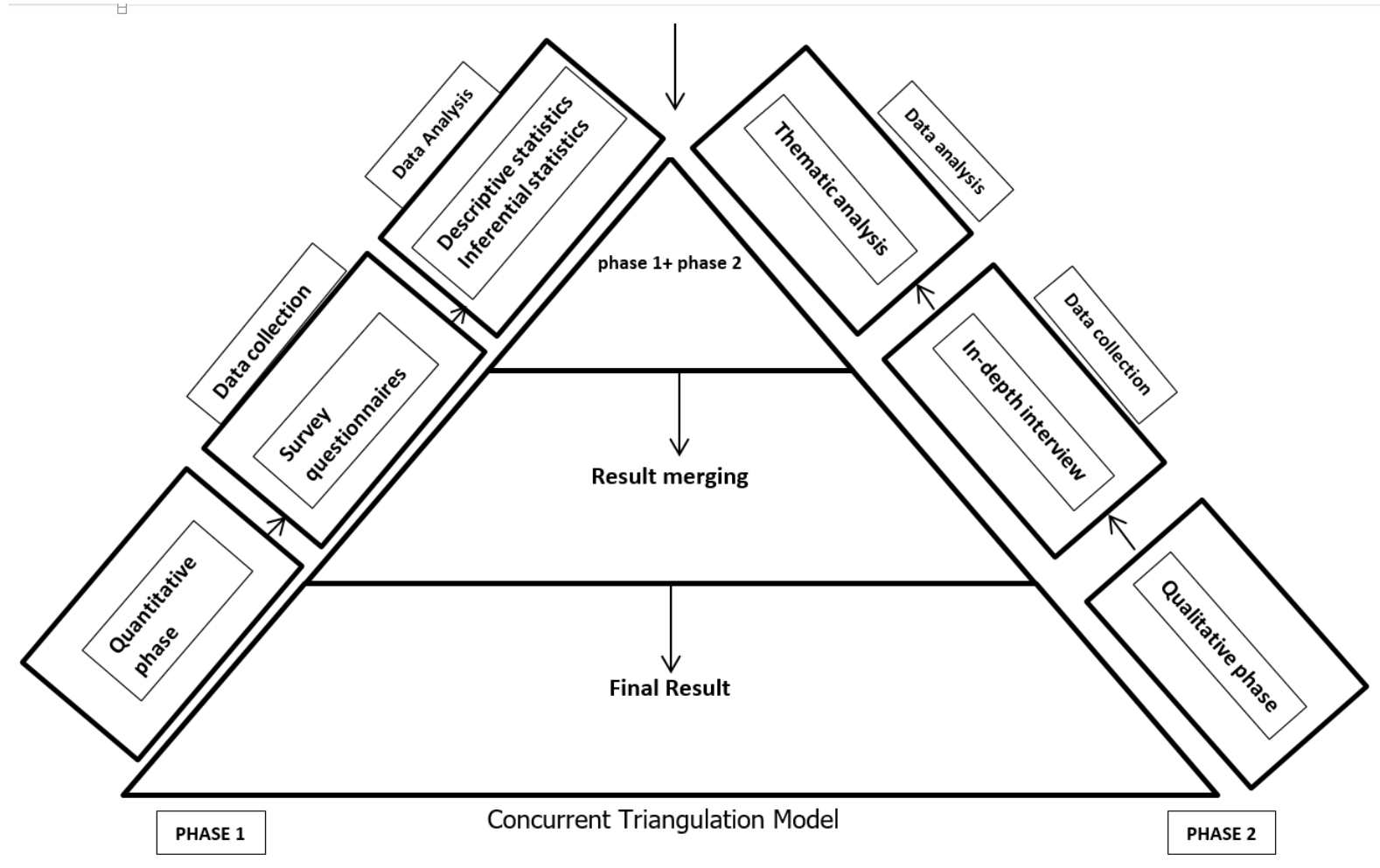

Figure 2: Concurrent Triangulation Model (source of diagram: Author, 2020)

From the distributed questionnaires, 300 questionnaires were completed and considered useable, 60 distributed face-to-face interview questions were duly completed and found useable for the study. A total of 360 questionnaires were collected, and found useable from a total of 410 questionnaires that were distributed for the study. A dedicated email account was set up using the YESWARE software where recipients were added from a preexisting list from the attendance list of participants of a workshop I Co - coordinated for an audience comprising of manufacturing industry workers, waste managers, employees of Ministry of Environment and some university lecturers specialized in the area of waste management and environmental science experts. A percentage of response rates was recorded at $73.17 \%$ and decline rate was $26.83 \%$ for questionnaire survey questions whereas a percentage of $85.71 \%$ of respondents responded to the face-toface interview and only $14.29 \%$ declined. From the total of 360 respondents, $79.44 \%$ of the respondents were recorded for response rate and $20.56 \%$ recorded for decline rate.

\section{RESULT AND DISCUSSION}

The distributed close ended questionnaires and faceto-face interviews conducted, produced data that were carefully analyzed and used in the concurrent triangulation model. The results were recorded and merged as presented in Table 1, Table 2, Table 3 and Table 4.

From Table 1, it can be deduced that the waste reduction steps in sustainable manufacturing system showed that recycling methods produced the highest number of response with a number of 156 respondents at $52 \%$, indicating that recycling of waste produced a non-toxic environment without a negative environmental impact. Re- use method recorded a high response of 54 respondents next to recycle method. A number of 36 respondents with $12 \%$ response were of the view that Re-manufacturing is a sustainable manufacturing method, while reduce and landfilling recorded 30 respondents with $8 \%$ responses respectively. Face-to-face interviews with 60 respondents was conducted and recorded in Table 2.

From Table 2, it can be deduced that the reuse method of sustainable manufacturing disposal method recorded 13 responses with $21.66 \%$, remanufacture had 08 responses with $13.33 \%$, reduce had 7 responses with $11.67 \%$, landfilling had 4 responses with $6.67 \%$ and recycling recorded the highest responses with 28 respondents at $46.67 \%$. From the 60 respondents, 28 respondents agreed that recycling method was the sustainable manufacturing method that best sooth the environment. 
Table 1: Results from survey questionnaires

\begin{tabular}{llcc}
\hline S/N & Sustainable Manufacturing disposal methods & Respondents & Percentage (\%) \\
\hline 1. & Land filing & 24 & 8.00 \\
2. & Reduce (Biodegradable composing) & 30 & 10.00 \\
3. & Re-cycle & 156 & 52.00 \\
4. & Remanufacturing & 36 & 12.00 \\
5. & Reuse & 54 & 18.00 \\
\hline & & 300 & $100 \%$ \\
\hline
\end{tabular}

Table 2: Results from Face-to-face interview with 60 respondents retrieved and found useable for sustainable manufacturing system.

\begin{tabular}{llcc}
\hline S/N & Sustainable Manufacturing disposal methods & Respondent & Percentage (\%) \\
\hline 1. & Reuse & 13 & 21.66 \\
2. & Remanufacture & 8 & 13.33 \\
3. & Recycle & 28 & 46.67 \\
4. & Reduce (Biodegradable composing) & 7 & 11.67 \\
5. & Landfilling & 4 & 06.67 \\
\hline & TOTAL: & 60 & $100 \%$ \\
\hline
\end{tabular}

Table 3: Table of concurrent triangulation model recording a merger of results from Tables 1 and Table 2.

\begin{tabular}{llllll}
\hline \multirow{2}{*}{ S/N } & $\begin{array}{l}\text { sustainable manufacturing } \\
\text { waste disposal method }\end{array}$ & $\begin{array}{l}\text { E-mail responses of } \\
\text { questionnaire survey }\end{array}$ & $\begin{array}{l}\text { Face-face interview } \\
\text { Respondents }\end{array}$ & Total & $\begin{array}{l}\text { Percentage } \\
(\%)\end{array}$ \\
\hline 1. & Landfilling & 24 & 13 & 37 & 10.27 \\
2. & Reduce & 20 & 8 & 38 & 10.55 \\
3. & Recycle & 156 & 28 & 184 & 51.11 \\
4 & Remanufacturing & 36 & 7 & 43 & 11.94 \\
5 & Reuse & 54 & 4 & 58 & 16.13 \\
\hline & TOTAL & 300 & 60 & 360 & $100 \%$ \\
\hline
\end{tabular}

Table 4: Results of Questionnaires and face-to-face Interview Respondents.

\begin{tabular}{|c|c|c|c|c|c|}
\hline $\mathrm{S} / \mathrm{N}$ & Questionnaires & $\begin{array}{l}\text { E-mail responses of } \\
\text { questionnaire survey }\end{array}$ & $\begin{array}{l}\text { Percentage } \\
(\%)\end{array}$ & $\begin{array}{l}\text { Face-face interview } \\
\text { Respondent }\end{array}$ & $\begin{array}{l}\text { Percentage } \\
(\%)\end{array}$ \\
\hline 1. & $\begin{array}{l}\text { Environmental } \\
\text { protection }\end{array}$ & T & 60.67 & (a) & 65.0 \\
\hline 2. & Social development & 74 & 24.67 & 13 & 21.67 \\
\hline \multirow[t]{2}{*}{3.} & $\begin{array}{l}\text { Economic } \\
\text { development }\end{array}$ & 44 & 14.66 & 8 & 13.33 \\
\hline & TOTAL: & 300 & $100 \%$ & 60 & $100 \%$ \\
\hline
\end{tabular}

The concurrent triangulation model recorded a merger of results from Tables 1 and 2 and showed Recycling recorded a total of 184 respondents at $51.11 \%$, Reuse recording a total of 58 respondents with $16.13 \%$, Remanufacture recording $11.94 \%$, Reduce recording a total of 38 respondents at $10.55 \%$, and lastly, Landfilling had 37 respondents with $10.27 \%$.From the results of the merger of phase 1 and phase 2, Recycling recorded the highest percentage of respondents with $51.11 \%$. Showing that half of the total respondents were of the view that recycling is the most appropriate method for sustainable manufacturing waste disposal.
Waste reduction was analyzed using the results of Questionnaires and face-to-face Interview of respondents in the area of the three fundamentals of sustainability: Social development, economic development and environmental protection. The results are recorded in Table 4.

From Table 4, it can be deduced that from a total of 360 respondents, environmental protection had the highest response with 182 respondents at $60.67 \%$, social development recorded 74 respondents with $24.67 \%$ and economic development recorded the least response with 44 responses $14.66 \%$ using the Questionnaire survey. Using the Face-face interview methods, the least responses emanated from 
economic development with 8 respondents at $13.33 \%$, 13 respondents for social development at $21.67 \%$ and then the highest response was recorded for environmental protection with 39 respondents at $65 \%$. Table 4 showed the merged results of both questionnaires survey and the Face-face interview for the three pillars of sustainability.

From a total of 360 respondents, environmental protection had the highest number of responses with 22 respondents at $61.3 \%$. 87 respondents agreed to social development with $24.17 \%$ while 52 respondents with $14.44 \%$ were of the opinion that economic development will enhance the world.

\section{VALIDATION OF RESULTS}

The results obtained from the concurrent triangulation model were validated using the reliability test. The internal consistency of the sustainable manufacturing systems mentioned was checked using the Cronbach alpha in the Table 6, the table showed values of Cronbach Alpha in a range of reliability for internal consistency.

From the computation, Using the rule of thumb $0 \geq$ 0.9 is excellent, $0 \geq 0.8$ is good, $0 \geq 0.7$ is acceptable, $0 \geq 0.6$ is quetionable, 0 0.5 is poor, and $\begin{array}{lll}0 & 0.4 & \text { is unacceptable, the values obtained was }\end{array}$ analyzed as 0.8160 with 82 questions in favor of recycling fell in the range of $0 \geq 0.8$ is good. The result for the reliability test for the highest consistency was recorded for recycling method at 0.8160 followed by Reuse method $(0.8100)$, reduce $(0.7760)$, Remanufacture (0.7550) and land filing method which had the least reliability of internal consistency results of 0.7340 . From the analysis, the Cronbach alpha result obtained for recycling had a reasonable consistency. The internal alpha value is between 0 and 1 and the value of 0.8000 is the expected value required to show a good internal consistency of items in the scale as recorded by Glien, 2003. The results were accepted because it was properly established by reliability analysis as compared to Glien 2003.

\section{PEARSON CORRELATION MATRIX}

The correlation matrix results shown in Table 6, measured the degree of linear relationship between the different sustainable manufacturing methods of waste disposal in this study. The results from the correlation coefficient showed that there is a positive correlation relationship existing between reuse methods and reducing waste and remanufacturing (Reduce $=0.1406$ ). The positive coefficient means that Re-use and reduce methods of waste disposal will produce a sound sustainable manufacturing system over time by reducing waste generated and controlling pollution in order to sustain the environment. A weak positive correlation relationship exists between remanufacture and reuse

(Remanufacture $=0.1880$ ). The positive correlation means that remanufacturing is a factor that will lead to sustainable manufacturing over time by relying on sustainable manufacturing system for manufacturing processes in our industries and factories. A weak correlation relationship exist between landfilling [1] and reuse [2] (landfilling=0.1802).

Table 5: Merged results of phase 1 and phase 2 of the concurrent Triangulation model. (Qualitative phase and Quantitative phase) for the three pillars of sustainable development.

\begin{tabular}{llcccc}
\hline S/N & & Questionnaire & Face-face interview & Merged & Percentage (\%) \\
\hline 1. & Environmental protection & 182 & 39 & 221 & 61.39 \\
2. & Social development & 74 & 13 & 87 & 24.17 \\
3. & Economic development & 44 & 8 & 52 & 14.44 \\
\hline & TOTAL & 300 & 60 & 360 & $100 \%$ \\
\hline
\end{tabular}

Table 6: results from Reliability Test using Cronbach Alpha.

\begin{tabular}{llll}
\hline S/N & $\begin{array}{l}\text { Sustainable Manufacturing disposal } \\
\text { methods }\end{array}$ & Cronbach Alpha & Number of Items \\
\hline 1. & Remanufacturing & 0.7550 & 69 \\
2. & Recycling & 0.8160 & 82 \\
3. & Reduce(composting) & 0.7760 & 70 \\
4. & Reuse & 0.8100 & 78 \\
5. & Land filing & 0.7340 & 61 \\
\hline
\end{tabular}


The positive coefficient means that land filling of materials not meeting recycling standards, will lead to sustainable manufacturing and improve sustainable manufacturing systems overtime. The result also showed a positive correlation relationship existing between Recycle and Reuse (Recycle=0.4023). The positive coefficient means that the Recycling waste and reuse of waste move in same direction, meaning that as reuse activities increases, Recycling activities will also increase as shown in the $P$ values of 0.000 for reuse and recycle which validates this statement (Table 7). This would lead to a good sustainable manufacturing in industries in the long run thereby encouraging manufacturing practices that will enhance recycling as a sustainable manufacturing waste disposal method to sustain methods of recycling in order to bring about pollution control and waste reduction for environmental sustainability. All the correlation coefficient showed that a positive correlation relationship existed between all the five different sustainable manufacturing methods indicating that all the variables tend to go up in response to one another. The correlation result is shown in Table 7.

\section{MULTIPLE REGRESSION TECHNIQUE}

The individual significance of the various sustainable manufacturing method were tested using the multiple regression technique and the result was presented in Table 8.
About fifteen percent ( $85 \%)$ of the systematic variation in sustainable manufacturing are explained together with the sustainable methods of waste disposal which are: Re-use, Reduce, Remanufacture, using landfills and Re-cycling of materials. The error term captured $15 \%$ remain of the systematic variations meaning that the concurrent triangulation model is good for predicting the statistical analysis of the data collected. There is a significant linear relationship between sustainable manufacturing system and sustainable manufacturing waste disposal methods as this was shown in the F-statistics value of 8.0809 .

Recycling had a positive coefficient of a 0.4460 and a significant influence on sustainable manufacturing system at $1 \%$ level of significance. Recycling variable passed the individual test of significance of $99 \%$ level of confidence.

The regression results revealed that:

1. Reduce (waste disposal method), had a negative coefficient and insignificant influence on sustainable manufacturing systems, waste reduction and pollution control.

2. Reuse had a positive coefficient and an insignificant influence on sustainable manufacturing systems, waste reduction and pollution control.

3. Remanufacturing had a positive coefficient and an insignificant influence on sustainable manufacturing systems, waste reduction and pollution control.

Table 7: correlation result for the five sustainable manufacturing waste disposal methods

\begin{tabular}{lllllll}
\hline S/N & $\begin{array}{l}\text { Sustainable manufacturing disposal } \\
\text { methods }\end{array}$ & Reuse & Reduce & Remanufacture & landfill & Recycle \\
\hline 1. & Reuse & 1 & - & - & - & - \\
2. & Reduce & 0.1406 & 1 & - & - & - \\
3. & Remanufacturing & 0.1880 & 0.5195 & 1 & - & - \\
4. & Landfilling & 0.1802 & 0.6073 & 0.6227 & 1 & \\
5. & Recycle & 0.4023 & 0.5046 & 0.4643 & 0.4878 & 1 \\
\hline
\end{tabular}

Table 8: Result of multiple regression analysis

\begin{tabular}{rlrrc}
\hline S/N & Sustainable manufacturing disposal methods & Coefficient & \multicolumn{1}{c}{ t-Test } & P-value \\
\hline 1. & Re-use & 1.8133 & 5.0540 & 0.0000 \\
2. & Reduce & -0.0998 & -1.0471 & 0.2966 \\
3. & Remanufacturing & 0.0377 & 0.3488 & 0.7276 \\
4. & Landfill & 0.0101 & 0.0916 & 0.9271 \\
5. & Recycle & 0.4460 & 4.9202 & 0.0000 \\
\hline
\end{tabular}

R- Square $=0.1681$

Adjusted R-square $=0.1473$

F-statistics $=8.0809$

Probability (F-statistics) $=0.000006$ 
4. Land filling had a positive coefficient and an insignificant influence on sustainable manufacturing systems, waste reduction and pollution control.

5. Re-cycling had a positive coefficient and significant influence on sustainable manufacturing systems, waste reduction and pollution control. Hence, it is selected as the most appropriate method for a properly organized sustainable manufacturing system.

\section{CONCLUSION}

1. The concurrent triangulation model has proved efficient in the determination of an ideal sustainable manufacturing system. From the analysis, recycling method of waste disposal proved to be the most appropriate method for sustainable manufacturing waste disposal method to power sustainable manufacturing systems.

2. In other to reduce waste and curb pollutions reliability test carried out using the Cronbach alpha (a) recorded values of recycling, reuse, reduce, remanufacture and landfill at $0.8160,0.8100$, $0.7760,0.7550$ and 0.7340 respectively. The Cronbach alpha (a) value of 0.8160 , for indicated that alpha value increased as the number of questions increased as a reasonable internal consistency value is between 0.8 and 0.9 which shows that from the index of association the value 0.8160 is considered Good.

3. From a total of 360 respondents, environmental protection had the highest number of responses with 22 respondents at $61.3 \%$. 87 respondents agreed to social development with $24.17 \%$ while 52 respondents with $14.44 \%$ were of the opinion that economic development will enhance the world.

4. From the concurrent triangulation model, results showed that Recycling recorded a total of 184 respondents at $51.11 \%$, Reuse recording a total of 58 respondents with $16.13 \%$, Remanufacture with 43 respondents recording $11.94 \%$, Reduce recording a total of 38 respondents at $10.55 \%$, and lastly, Landfilling had 37 respondents with $10.27 \%$. From the results of the merger of the Quantitative analysis of phase 1 and qualitative analysis of phase 2 , Recycling recorded the highest percentage of respondents with $51.11 \%$. Showing that half the total of 360 respondents were of the view that recycling is the

5. In order to achieve a sustainable manufacturing system for a viable environment. Results of multiregression analysis showed that $\mathrm{R}$-square had a value of 0.1681 , Adjusted R-square was 0.1473 , F- statistics was 8.0809 and the Probability (Fstatistics) was recorded at 0.000006 .

\section{ACKNOWLEDGEMENT}

The Author is particularly grateful to Prof. Kingsley Ufuoma Omoyibo (Professor of Globalization, Development, Socio-psychology, Gender Issues, Crime and delinquency and human resource management),my husband who created an enabling environment for me to carry out this original research from start to finish. I am particularly grateful to my university were I lecture, Igbinedion University Okada, for giving me the push to write original researches for the benefits of all.

\section{REFERENCES}

[1] Adefemi, S.O., and Awokunmi, E.E. The Impact of municipal solid waste disposal in Ado Ekiti metropolis Ekiti state, Nigeria, African Journal of Environmental Science and technology 3; 186189, 2009.

[2] Allan, F., Samir. Valentina, Clean green Integration focused on waste reduction technique. International journal of Cleaner Production 137:569-578, 2016.

[3] Angelis, J., and Fernandes, B. Innovative Lean; work practice and product process improvement International Journal of Lean Six Sigma 3 (1): 7484, 2012.

[4] Ezeah, C. and Roberts, C. waste governance agenda in Nigerian cities: A comparative analysis. Habitat International 41 (1): 121-128, 2014

[5] Haghi, A.K., Waste management: Research advances to convert waste to wealth. Hauppauge, New York: Nova Science Publishers, 2010.

[6] Heilala, J., Vatanen, S., Tonteri, H. and Montenen, J., Simulation based sustainable manufacturing system design. Proceedings of the 2008 winter simulation conference PP 1922-1920, 2008

[7] Ogbazi, J.U. Alternative planning approaches and the Sustainable cities program in Nigeria. Habitat International 40 (3), 109-118, 2013.

[8] Ogunmakinde, O.E, An Assessment of material waste disposal method in Nigerian Construction Industry. Recycling 4 (13), 1-15, 2019.

[9] Sangodoyin, A.Y, and Ipadeola, S.F Hazardous wastes, assessing the efficacy of Structure and approaches to management in Nigeria. Journal of 
Environmental Management and Health. II (II), 39-46, 2000.

[10] Schroeder, D.M and Robinson, A.C. Green is free creating sustainable competitive advantage through green excellence, Organizational Dynamics. 39(2), pp. 345-352, 2010.

[11] Thilo Kroll and Neri Melinda, Designs for mixed Methods ,Using Mixed methods in Disability and Rehabilitation, Research Journal of Association of Rehabilitation Nurses 30 (1): 106-113, 2005.
[12] UNEP, Developing integrated solid waste management plan training manual. (ISWM plan) Volume 4 Osaka, Japan United Nations Environmental Program, 2009.

[13] Gliem J. A. and Gliem R, R, "Calculating, Interpreting and Reporting Cornback's Alpha (a) Coeficient for Likert-type scales", Midwestern Research to produce Conference in Adult Continuing and Community Education, Columbus Ohio, Ohio State University, pp. 82-88, 2003. 